\title{
Global evidence on the prevalence and impact of online gender-based violence (OGBV)
}

Jacqueline Hicks

Institute of Development Studies

8 October 2021

\section{Question}

What global evidence is there on the nature and prevalence of online gender-based violence? What are some examples of the impact of online gender-based violence at the societal level?

\section{Contents}
1. Summary
2. Definitions
3. Prevalence
4. Nature
5. Perpetrators
6. Impact
7. References other Government departments, but the views and opinions expressed do not necessarily reflect those of FCDO, the UK Government, K4D or any other contributing organisation. For further information, please contact helpdesk@k4d.info. 


\section{Summary}

This rapid review updates a previous report (Fraser and Martineau-Searle, 2018) with evidence from 2018 onwards. It finds an evidence base on online gender-based violence (OGBV) covering a wider range of countries than the previous report. Due to the diversity of actions the category of OGBV covers, generalisations should be made with caution.

Some key findings on the nature and prevalence of OGBV include:

- The most recent surveys show a prevalence of OGBV ranging from $16 \%$ to $58 \%$ depending on the question asked, and the demographic features of respondents such as age and gender.

- Men and boys also experience online abuse in high numbers, but it is less likely to be gender-based.

- Several studies from different countries identify Facebook as the top location for incidents of OGBV.

- Higher levels of online harassment and abuse are faced by people with intersecting inequality factors (women of colour, LGBTQ+ women with disabilities), women in abusive intimate partner relationships, women in marginal social locations, and women in leadership positions.

- According to victim-survivors, perpetrators are more likely to be unknown and acting alone, but large numbers are known to the victims. Perpetrators themselves report divergent, multifaceted and often over-lapping motivations for their actions.

- Analysis of underlying drivers of OGBV highlights an overarching theme of power and control, and heteronormative expectations around gender roles and sexual practice.

Many authors recommend that OGBV be understood as part of a continuum of abuse where normalised behaviours, such as sexual harassment in public spaces, shade into behaviours widely recognized as criminal, such as physical assault:

"The normalization of misogyny and abuse online both reflects and reinforces systemic inequalities."

(Suzor et al., 2020, p.84)

The societal impact of OGBV includes:

- Media freedom is compromised: almost a third of women journalists report selfcensorship on social media.

- Democracy is undermined: female political leaders say that gendered disinformation campaigns discourage women from political involvement. Across the general population, women who speak about political issues face higher rates of "harassment" online.

- Economic losses resulting from lost productivity: one estimate puts the cost of OGBV to EU countries at between $€ 49$ to $€ 89$ billion per year.

- A 'climate of unsafety' prevails: there is strong evidence on the integration of online and offline gender-based violence. 
Evidence base: The number of surveys about self-reported experiences with online harassment has increased rapidly. The majority of the research found during the course of this rapid review came from international and domestic non-governmental organisations and think-tanks.

Academic research studies were also found, including several literature reviews.

\section{Definition, nature and novelty of OGBV}

The terminology in this space includes "online gender-based violence" (OGBV), "cyber violence against women and girls" (Cyber VAWG), and "technology-facilitated gender-based violence" (TFGBV), amongst others. They all refer to similar practices as defined below, with differences of scope. For example, TFGBV allows for non-internet technologies, and reference to gender rather than women allows for the inclusion of transgender, non-binary and gender-nonconforming people, as well as men.

This report defines OGBV as an "action by one or more people that harms others based on their sexual or gender identity or by enforcing harmful gender norms. This action is carried out using the internet and/or mobile technology and includes stalking, bullying, sexual harassment, defamation, hate speech and exploitation" (Hinson et al., 2018).

\section{The online nature of OGBV enables:}

- The possibility for cross-jurisdictional abuse.

- The ability for abusers to remain anonymous.

- The constant access to the survivor through connected devices.

- The perpetual nature of digital content.

- The ease with which content can be copied.

- The breadth of audiences witnessing the abuse.

- Opportunities for abusers to join forces on digital platforms to organise attacks.

Dunn (2020, p.4).

A frequently cited categorisation of types of OGBV is:

- Hacking: the use of technology to gain unauthorised access to systems or information, e.g. violation of passwords.

- Impersonation: the use of technology to assume the identity of someone else, e.g. creating a fake profile for social networking sites.

- Surveillance / Tracking: the use of technology to stalk and monitor someone else's activities, e.g. keeping track of web browsing or GPS tracking via a mobile phone.

- Harassment / Spamming: the use of technology to continuously contact, annoy, threaten, and/or scare someone. 
- Recruitment: the use of technology to lure people into potentially violent situations, e.g. traffickers using chat rooms.

- Malicious Distribution: the use of technology to manipulate and distribute personal and/or defamatory content, e.g. 'doxing' (publicly revealing private information), and 'revenge pornography.'

(VAW Learning Network, 2013)

More recently, the category of gendered disinformation has gained prominence, and can be defined as: "a subset of online gendered abuse that uses false or misleading gender and sexbased narratives against women, often with some degree of coordination, aimed at deterring women from participating in the public sphere. It combines three defining characteristics of online disinformation: falsity, malign intent, and coordination" (Jankowicz et al., 2021, p.1).

\section{Prevalence of OGBV}

\section{A number of studies have been published in the last two years detailing self-reported OGBV in a wide range of countries.}

Comparing the results of different studies on OGBV prevalence is not straightforward due to methodological differences, including the specific question asked, the characteristics of respondents, and whether the survey is anonymous. Keeping these differences in mind, Table 1 below presents some of the recent headline findings on OGBV prevalence from different countries. This is not a comprehensive list of all existing studies, but only a selection of those found during the course of this rapid review. 
Table 1: Selected recent survey results on OGBV prevalence

\begin{tabular}{|c|c|c|c|}
\hline Question & Geography & $\begin{array}{l}\text { Percent of } \\
\text { women }\end{array}$ & Respondents \\
\hline \multirow{4}{*}{$\begin{array}{l}\text { Have experienced OGBV. } \\
\text { OGBV was defined by } \\
\text { interviewers in a discussion with } \\
\text { respondents. } \\
\text { (lyer et al., 2020) }\end{array}$} & \multirow{4}{*}{$\begin{array}{l}\text { Average of } 5 \text { African } \\
\text { cities: } \\
\text { Addis Ababa, Nairobi, } \\
\text { Kampala, Dakar and } \\
\text { Johannesburg. }\end{array}$} & \multirow{4}{*}{$\begin{array}{l}28 \% \\
\text { experienced } \\
\text { some form of } \\
\text { OGBV. }\end{array}$} & \multirow{4}{*}{$\begin{array}{l}\text { Women } \\
\text { Age: } 18-65 \\
3306 \text { face-to-face surveys } \\
\text { with women that use the } \\
\text { internet at least once a } \\
\text { week found through } \\
\text { 'convenience sampling.' }\end{array}$} \\
\hline & & & \\
\hline & & & \\
\hline & & & \\
\hline \multirow{5}{*}{$\begin{array}{l}\text { Have personally experienced } \\
\text { some form of online } \\
\text { harassment on social media } \\
\text { platforms. } \\
\text { Defined as an action by one or } \\
\text { more people that harms others } \\
\text { based on their sexual or gender } \\
\text { identity. } \\
\text { (Plan International, 2020) }\end{array}$} & \multirow{5}{*}{$\begin{array}{l}\text { Average of } 22 \text { countries: } \\
\text { Australia, Benin, Brazil, } \\
\text { Canada, Colombia, Dominican } \\
\text { Republic, Ecuador, Germany, } \\
\text { Ghana, Guinea, India, } \\
\text { Indonesia, Japan, Kenya, } \\
\text { Netherlands, Nigeria, Norway, } \\
\text { Philippines, Spain, Thailand, } \\
\text { USA, Zambia. }\end{array}$} & \multirow{5}{*}{$\begin{array}{l}58 \% \\
\text { experienced } \\
\text { some form of } \\
\text { online } \\
\text { harassment. }\end{array}$} & Girls and women \\
\hline & & & Age: $15-25$ \\
\hline & & & 14,071 online and \\
\hline & & & survey firms sampling \\
\hline & & & \\
\hline \multirow{2}{*}{$\begin{array}{l}\text { Have experienced online } \\
\text { abuse. } \\
\text { Includes, but is not limited to, } \\
\text { threatening messages, sexual } \\
\text { harassment and the sharing of } \\
\text { private images without consent. }\end{array}$} & \multirow[t]{2}{*}{$\begin{array}{l}\text { Average of } 180 \\
\text { countries. }\end{array}$} & \multirow{2}{*}{$\begin{array}{l}52 \% \\
\text { experienced } \\
\text { some form of } \\
\text { online abuse. }\end{array}$} & $\begin{array}{l}\text { Young women and girls. } \\
\text { All ages. }\end{array}$ \\
\hline & & & $\begin{array}{l}8,109 \text { online respondents } \\
\text { from a survey distributed } \\
\text { by WWWF and Girl } \\
\text { Guides via their social } \\
\text { media. }\end{array}$ \\
\hline \multirow{3}{*}{$\begin{array}{l}\text { Have faced sexual } \\
\text { harassment online. } \\
\text { Includes cyberstalking, doxing, } \\
\text { sending sexually explicit images } \\
\text { without consent, leaking } \\
\text { personal information. }\end{array}$} & \multirow{4}{*}{$\begin{array}{l}\text { Average of } 6 \text { Indian cities } \\
\text { and small towns in } \\
\text { Karnataka, Kerala and } \\
\text { Tamil Nadu. }\end{array}$} & \multirow{4}{*}{$\begin{array}{l}31 \% \\
\text { experienced } \\
\text { online sexual } \\
\text { harassment. }\end{array}$} & Women \\
\hline & & & Age: $19-23$ \\
\hline & & & $\begin{array}{l}881 \text { college students in a } \\
\text { self-administered, } \\
\text { anonymized survey. }\end{array}$ \\
\hline (Gurumurthy et al., 2019) & & & \\
\hline \multirow{4}{*}{$\begin{array}{l}\text { Have experienced online } \\
\text { sexual harassment. } \\
\text { Self-defined. } \\
\text { (Pew, 2021) }\end{array}$} & \multirow[t]{4}{*}{ USA } & \multirow{4}{*}{$\begin{array}{l}16 \% \text { of adult } \\
\text { women. }\end{array}$} & Women. \\
\hline & & & Age: Over 18 \\
\hline & & & $\begin{array}{l}10,093 \text { adults, including } \\
\text { men. }\end{array}$ \\
\hline & & & $\begin{array}{l}\text { Weighted, representative } \\
\text { sample of the U.S. adult } \\
\text { population. }\end{array}$ \\
\hline
\end{tabular}




\section{Men and boys also experience online abuse in high numbers, but it is less likely to be gender-based.}

Most of the studies in Table 1 only survey women and girls. The exception is the Pew 2021 study of online harassment in the US which shows that men are more likely than women to say they have experienced any form of harassment online (43\% vs. 38\%). Men are more likely to say they have been called an offensive name than women (35\% vs. $26 \%$ ), and to say they have been physically threatened online ( $16 \%$ vs. $11 \%$ ). Among adults who have been harassed online, roughly half of women ( $47 \%$ ) say they think they have encountered harassment online because of their gender, whereas $18 \%$ of men who have been harassed online say the same.

Pew conducted the same study in 2014 and 2017. Notably, online harassment as a general category across all adults remained static at $41 \%$ from 2017 to 2021 , but the percentage of women who report having been sexually harassed online in the US has doubled since 2017, from $8 \%$ to $16 \%$.

\section{Nature of OGBV}

These new studies, with a wider geographic spread than previous studies, also give some detail about the types of OGBV encountered, and the platforms where it is encountered most often.

\section{Across the world, Facebook is highlighted as the most frequent location named for OGBV.}

The Plan International research (2021) covering 22 countries found that it is on Facebook that girls and women feel particularly unsafe, with $39 \%$ reporting they have experienced "harassment" there, compared with $23 \%$ for Instagram and $14 \%$ for Whatsapp.

Facebook is also cited as the top location for incidents of "online gender-based violence" in the survey of five African cities (lyer et al., 2020), with $71.2 \%$ of all incidents occurring there compared with around $30 \%$ on Whatsapp and around $10 \%$ on Instagram.

Gurumurthy et al. (2019) similarly report that the most common applications where Indian respondents had faced harassment were Facebook (61\%) and WhatsApp (47\%).

In a global survey of 901 journalists (714 women) from 125 countries (Posetti et al., 2021), Facebook was rated the most dangerous of the top five platforms/apps used, with nearly double the number of respondents rating Facebook "very unsafe" compared to Twitter. This is despite similar figures for 'most frequently used platform', with $77 \%$ saying Facebook and $74 \%$ saying Twitter.

Pew International does not name individual sites in its research, noting only that three-quarters of Americans who have been the target of "online harassment" say that their most recent experience occurred on social media, compared with $25 \%$ for online forums, and $24 \%$ on texting or messaging apps. However, there are gender differences, with women more likely to say their most recent experience of harassment was on social media compared to men (a 13-point difference). Men are more likely to report their most recent experience was while using an online forum or discussion site or while online gaming (both with a 13-point gap). 
These figures should be understood in the context of the popularity of Facebook. For example, Plan International (2021) reports that the platforms used most by respondents are WhatsApp $(60 \%)$, Instagram (59\%) and Facebook (53\%). However, the study does not report on the intensity of use by respondents. The research from India (Gurumurthy et al., 2019) notes that Facebook is the most commonly used platform with an open public chat space $(57 \%$ of respondents report usage), compared to WhatsApp which is a closed messaging service $(93 \%$ of respondents report usage).

Platform experiences can also intersect. In the research on India by Gurumurthy et al. (2019), some interview respondents reported that men who are turned down on dating platforms shadow women on platforms such as Facebook and harass them with repeated 'friend requests'. Posetti et al. (2021, p.14) also report that "online violence frequently jumps platforms" for female journalists.

\section{Sexualised harassment is a particularly prevalent form of online abuse aimed at women.}

It becomes impossible to make meaningful comparisons between studies about the type of OGBV as they group behaviours differently. For example, Plan International (2020) uses nine categories of behaviour while lyer et al. (2020) uses three. Figure One below presents the average values of type of "harassment" faced by women and girls from their study of 22 countries. The report does not disaggregate by country or region.

Figure One: Percentage of girls and women facing different types of harassment.

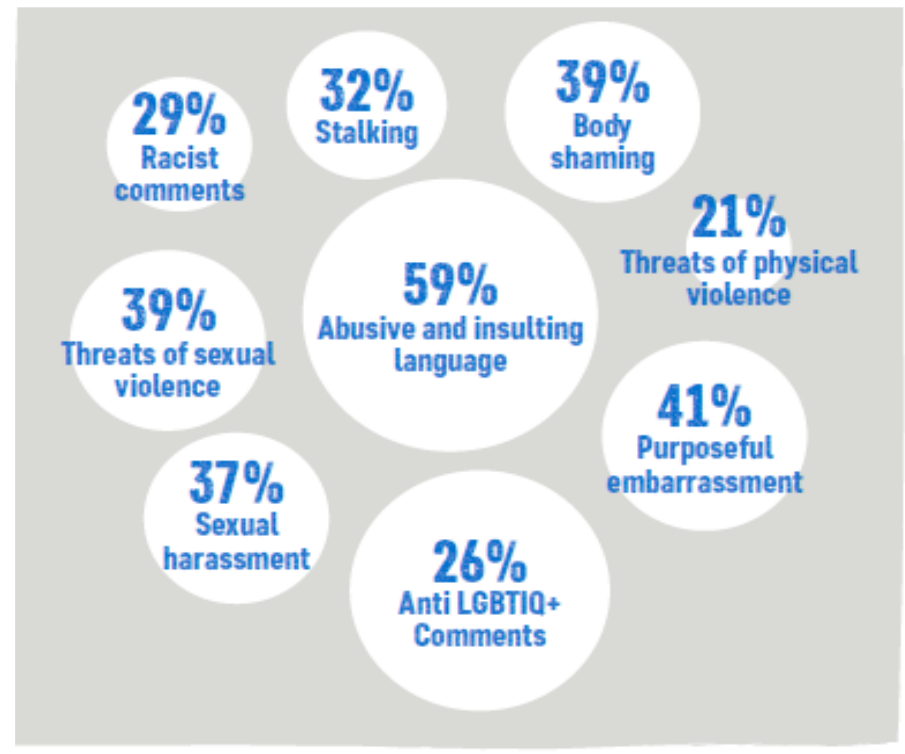

Source: Plan International (2020, p.17) Reproduced with permission

What emerges in general across all the studies is the high levels of sexualised harassment faced by women and girls - 36\% of those reporting "OGBV" in the African cities received unwelcome sexual advances online (lyer et al., 2020), while in India 30\% of the college students who reported "harassment" said they had received sexually explicit images without their consent (Gurumurthy et al., 2019). The Pew (2021) study of the US shows only $16 \%$ of adult women 
reporting encounters with online sexual harassment, this figure rises to $33 \%$ of all women aged under 35.

Dunn (2020, p.7) also detects elements of reinforcing gender roles in the attacks against women described in the research by Gurumurthy et al. (2019). "Some were 'mob-led castigation[s] of 'defiant' women, and others targeted nonheteronormative women and transwomen in an effort to 'gendertroll' [using gender-based insults] them."

\section{While similarities exist in OGBV the world over, their specific manifestations can reflect different contexts and vulnerabilities.}

In a review of the evidence on OGBV, Dunn (2020, p.16) notes that:

- Women, transgender and gender-nonconforming people with intersecting inequality factors, such as women of colour, LGBTQ+ women and/or people with disabilities, can face higher levels of online harassment and abuse compared to white, heterosexual, cis-gendered and/or able-bodied women.

- Women in abusive intimate partner relationships are likely to experience OGBV at the hands of their intimate partners.

- Women in leadership positions, such as politicians, human rights defenders and journalists, experience significantly higher levels of abuse online, particularly if they are speaking about equality issues or on issues traditionally dominated by men.

Describing the different social and political contexts for women in each part of India, Gurumurthy et al. (2019) find that digitally-mediated spaces in each of the contexts of study are shaped by the idiosyncrasies of local history, with specific manifestations of patriarchal social norms. In particular, the authors find that women from marginal social locations (such as 'lower' social castes) face particularly heinous forms of gender trolling.

\section{Perpetrators of OGBV}

Because these studies are self-reported experiences of OGBV, data on the perpetrators relies mostly on the perception or knowledge of those who have experienced OGBV rather than coming from the perpetrators themselves.

\section{According to victim-survivors, perpetrators are more likely to be unknown and acting alone, but in many cases they are known to the victims.}

In the 2020 study from 22 countries, Plan International's respondents report that "harassment" has been perpetrated by various categories of people they do not know personally in the majority of cases, but that they have also experienced "harassment" from friends, colleagues or partners in many cases (see Figure Two below).

In the study of African cities (lyer et al., 2020), $57 \%$ of the respondents who had experienced "OGBV", say that only one specific person was responsible for the incidents, and in $23 \%$ of the cases, multiple people were involved. 
The data from India (Gurumurthy et al. (2019) shows that $26 \%$ of the respondents who had faced "cyberviolence" reported that the identity of their perpetrators was known to them, whereas $51 \%$ reported that the perpetrator was unknown.

Figure 2: Percentage of surveyed girls/young women who report that they, or a girl/young woman they know, have been harassed by a perpetrator belonging to the following groups.

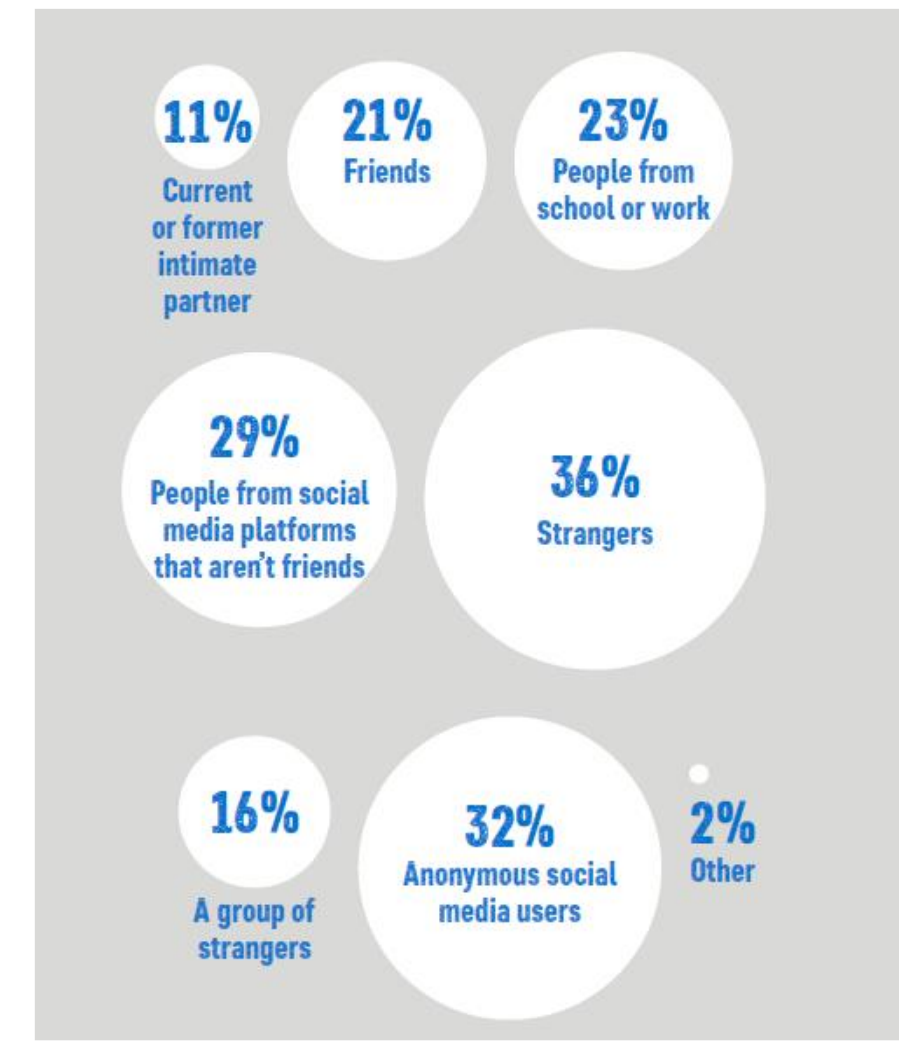

Source: Plan International (2020, p.26) Reproduced with permission

\section{Perpetrators' direct motivations are multifaceted, and linked with cultural expectations of masculinity and new norms of digital society.}

One survey about online image-based sexual abuse includes self-reporting from the perpetrators themselves as well as the victim-survivors (Henry et al., 2020). With over 6000 respondents from the UK, New Zealand and Australia, the survey captures a range of insights into the practice of non-consensual taking, sharing and threats to share nude or sexual images online.

Reporting that $17.5 \%$ of all respondents had engaged in at least one form of "image-based sexual abuse perpetration", the survey found that there were "divergent, multifaceted and often over-lapping motivations for engaging in these behaviours, including revenge, sexual gratification, social status building or financial gain", but that "an overarching theme across these different motivations was power and control" (p.13). The authors continue that "many respondents did not appear to recognise the harms caused to victims. Even when respondents 
described their motivations as to 'control', 'embarrass' or 'get back at the person', they also labelled them as 'funny' or 'sexy'” (p.77).

Beyond the perpetrators' self-reported motivations in surveys, the authors of this study (Henry et al, 2020) include information from qualitative interviews to identify "underlying drivers" of image-based sexual abuse. Their wider analysis draws from community, cultural and structural factors related to gender and sexuality, noting "perpetrator performances of celebrated forms of masculinity, and culturally specific and heteronormative expectations around gender roles, sexuality and sexual practice" (p.13).

The authors also note the "broader social context of contemporary digital society, including the cultural obsession with visuality and realism, the proliferation of user-generated content (including amateur pornography) and the commodification of both content and users" (p.14). They argue that these features of digital society means that "the non-consensual taking or sharing of nude or sexual images has become a normalised practice, constituting a form of 'social currency' and a conduit in which to engage in 'impression management' and build social status among groups of peers" (p.13).

\section{Societal Impact of OGBV}

\section{Multiple studies document the psychological and health impacts to individuals experiencing OGBV.}

A growing and robust body of evidence from surveys and interviews has documented the negative psychological, social, and reproductive health outcomes for victim-survivors of OGBV. (Fraser and Martineau-Searle, 2018; Henry and Powell, 2018; Backe et al., 2018).

This is confirmed by the most recent research. For example, the survey of Indian college students (Gurumurthy et al., 2019) notes that $28 \%$ of those who faced "cyberviolence" felt anxious or depressed, and $6 \%$ reported to have attempted some form of self-harm.

\section{At the societal level, OGBV impacts media freedom.}

A substantial new piece of research surveys 901 journalists (714 women) from 125 countries, has interviews with 173 international journalists and editors, and assesses over 2.5 million posts on Facebook and Twitter directed at two prominent women journalists (Posetti et al., 2021).

The research details high levels of self-censorship as a result of OGBV where journalists control what they say to avoid criticism. In the survey, when asked "How does the level of online violence you experience affect your journalism practice and your interaction with sources/audiences?", $30 \%$ of the women journalists surveyed answered that they selfcensored on social media. $20 \%$ described how they withdrew from all online interaction. Selfcensorship was also a response noted by many interviewees (Posetti et al., 2021, p.13). Similar findings are found by other research on the impact of OGBV on female journalists. For example, in a survey of 110 female journalists in Pakistan, 8 out of 10 respondents said they have selfcensored in order to counter online violence (Kamran, 2019).

Posetti et al. (2021, p.6) conclude that "online violence against women journalists is designed to: belittle, humiliate, and shame; induce fear, silence, and retreat; discredit them professionally, 
undermining accountability journalism and trust in facts; and chill their active participation (along with that of their sources, colleagues and audiences) in public debate... amounting to an attack on democratic deliberation and media freedom, encompassing the public's right to access information."

\section{OGBV also undermines democracy by discouraging politicians and those who speak about political issues.}

Recent research shows the impact of online abuse on the formal involvement of women in politics. Oates et al. (2019) analyse twitter responses to Democratic Party candidates for the 2020 U.S. Presidential primary election. They find that women candidates are frequently marginalized and attacked on character and identity issues that are not raised for their male counterparts. Commenting on this research, Thakur and Hankerson (2021, p.27) suggest that "gendered disinformation can shift the discourse away from policy issues to the personal. By trying to regularly refute personal attacks and falsehoods, women candidates will have less time to focus on substantive issues and the wider discussion about them will follow that pattern as well."

Di Meco's research is based on interviews with over 85 women leaders in politics from 28 countries, including three former Prime Ministers and one former president. She finds evidence that "gendered disinformation campaigns" create barriers for women in politics to succeed, and reports that many of the interviewees feel that such campaigns can make other women who are interested in politics more likely to reconsider their ambitions.

Plan International's global study (2020) found that girls who spoke about political issues such as race, feminism and human rights faced higher rates of "harassment" online compared to girls and young women who did not speak out about political issues.

\section{OGBV directly facilitates offline violence, and creates 'climates of unsafety' within society.}

There is a large body of evidence tracing the links between online and offline gender-based violence in a wide variety of circumstances.

Some research documents correlations between in-person abuse and technology-facilitated stalking (Aghtaie et al., 2018; Marganski and Melander, 2018). Interviews with victim-survivors of image-based sexual abuse demonstrate that it is often perpetrated as part of a pattern of domestic violence (Henry et al., 2020).

The research on journalists by Posetti et al. (2021) shows that $20 \%$ of survey respondents identifying as women said they had been attacked or abused offline in connection with online violence they had experienced. The authors describe offline violence against journalists as "seeded online" (p.16).

Amnesty International's research (2017), shows that $41 \%$ of women who had experienced "online abuse" or "harassment" said that on at least one occasion, these online experiences made them feel that their physical safety was threatened. 
Reviewing the literature on the links between online and offline GBV, Suzor et al. (2018) quote Stanko's (1990) concept of "climates of unsafety" as key to understanding the full impact of OGBV. This allows for a broader understanding of the fears some women experience from the lived reality of their everyday lives rather than focusing on "rational" or "irrational" responses to crime statistics (Walklate, 2007, p.90).

\section{The economic costs of OGBV are difficult to estimate, but likely to be substantial.}

The economic costs of OGBV for Europe are estimated in a book-length study prepared for the European Parliament by the European Parliamentary Research Service (Lomba et al, 2021). The authors estimate that the cost of OGBV to individuals and society among EU countries is between $€ \mathbf{4 9 . 0}$ to $€ \mathbf{8 9 . 3}$ billion per year. They state: "The largest cost category was the monetised value of the loss in terms of quality of life, which accounted for more than half of the overall costs (about $60 \%$ for cyber harassment and about $50 \%$ for cyber stalking). Labour market impacts were also found to be substantial, together accounting for approximately $30 \%$ for cyber harassment and $35 \%$ for cyber stalking, the higher costs for the latter owing to lower labour force participation. Healthcare costs and legal costs, while contributing less to overall costs, were nonetheless substantial" (p.II).

In their survey of journalists, Posetti et al. (2021, p.13) find that "employment and productivity impacts reported by the women survey respondents included missing work to recover from online violence (11\%), making themselves less visible (38\%), quitting their jobs (4\%), and even abandoning journalism altogether $(2 \%)$. Linked to this was the professional discreditation of online violence targets. The interviewees confirmed this pattern."

\section{Societal impacts are not uniformly distributed, depending on race, nationality and social standing.}

Looking at the intersection of gender and race, out of a sample of 778 women, Amnesty International (2018) found that black women journalists and politicians in the US and UK were $84 \%$ more likely to be the target of hate speech online compared to their white female counterparts.

In their global survey of journalists, Posetti et al. (2021) report that over half (53\%) of the women identifying as Arab said they had experienced offline attacks they think were seeded online, compared to $11 \%$ for white women and $20 \%$ overall. The authors say that their research "highlights the ways in which other forms of discrimination - such as racism, homophobia and religious bigotry - intersect with sexism and misogyny to worsen and deepen women journalists' experiences of online violence" (p.22).

Based on a consultation between tech companies, civil society organisations and women in public life, the Web Foundation (2020) report that "while more prominent journalists and politicians often receive more abuse, they may also have better access to resources like digital training, or media and legal support. In journalism, freelancers are less likely than journalists employed by a specific outlet to have access to tools and support." 


\section{References}

Aghtaie, N., Larkins, C., Barter, C., Stanley, N., Wood, M., \& Øverlien, C. (2018). Interpersonal violence and abuse in young people's relationships in five European countries: online and offline normalisation of heteronormativity. Journal of Gender-Based Violence, 2(2), 293310. doi:10.1332/239868018x15263879270302

Amnesty International. (2017). Amnesty reveals alarming impact of online abuse against women. https://www.amnesty.org/en/latest/press-release/2017/11/amnesty-reveals-alarmingimpact-of-online-abuse-against-women/

Amnesty International. (2018). Women abused on Twitter every 30 seconds - new study. https://www.amnesty.org.uk/press-releases/women-abused-twitter-every-30-seconds-newstudy

Backe, E. L., Lilleston, P., \& McCleary-Sills, J. (2018). Networked individuals, gendered violence: A literature review of cyberviolence. Violence and Gender, 5(3), 135-146. doi:10.1089/vio.2017.0056

Di Meco, L. (2019). \#ShePersisted women, politics, \& power in the new media world. The Wilson Center.

https://static1.squarespace.com/static/5dba105f102367021c44b63f/t/5dc431aac6bd4e791 3c45f7d/1573138953986/191106+SHEPERSISTED_Final.pdf

Dunn, S. (2020). Technology-facilitated gender-based violence: An overview. Centre for International Governance Innovation. http://www.jstor.org/stable/resrep27513

Fraser, E. and Martineau-Searle, L. (2018). Nature and prevalence of cyber violence against women and girls. VAWG Helpdesk Research Report No. 211.

https://www.gov.uk/research-for-development-outputs/nature-and-prevalence-of-cyberviolence-against-women-and-girls

Gurumurthy, A., Vasudevan, A. \& Chami, N. (2019). Born digital, born free? A socio-legal study on young women's experiences of online violence in South India. IT for Change. https://itforchange.net/sites/default/files/1662/Born-Digital_Born-Free_SynthesisReport.pdf.

Henry, N. and Powell, A. (2018). Technology-facilitated sexual violence: A literature review of empirical research. Trauma, Violence \& Abuse, 19(2), 195-208.

doi:10.1177/1524838016650189=

Henry, N., McGlynn, C., Flynn, A., Johnson, K., Powell, A., \& Scott, A. J. (2020). Image-based Sexual Abuse. Routledge. doi:10.4324/9781351135153

Hinson, L., Mueller, J., O’Brien-Milne, L., \& Wandera, N. (2018). Technology-facilitated gender based violence: What is it and how do we measure it? Washington: International Centre for Research on Women. https://www.icrw.org/publications/technology-facilitated-genderbased-violence-what-is-it-and-how-do-we-measure-it/

lyer, N., Nyamwire, B., \& Nabulega, S. (2020). Alternate realities, alternate internets: African feminist research for a feminist internet. Pollicy. https://www.apc.org/en/pubs/alternaterealities-alternate-internets-african-feminist-research-feminist-internet

Jankowicz, N., Hunchak, J., Pavliuc., A., Davies, C., Pierson, S., \& Kaufmann, Z. (2021). Malign creativity: How gender, sex, and lies are weaponized against women online. Wilson Center Science and Technology Innovation Program, https://www.wilsoncenter.org/sites/default/files/media/uploads/documents/Report\%20Malig 
n\%20Creativity\%20How\%20Gender\%2C\%20Sex\%2C\%20and\%20Lies\%20are\%20Weapo nized\%20Against\%20Women\%200nline_0.pdf

Kamran, H. (2019). Hostile bytes: A study of online violence against women journalists. Media Matters for Democracy. http://digitalrightsmonitor.pk/wp-content/uploads/2019/11/HostileBytes.pdf

Lomba, N., Navarra, C. \& Fernandes M. (2021). Combating gender-based violence: Cyber violence European added value assessment. European Parliamentary Research Service March 2021.

https://www.europarl.europa.eu/RegData/etudes/STUD/2021/662621/EPRS_STU(2021)66 2621_EN.pdf

Marganski, A. and Melander, L. (2018). Intimate partner violence victimization in the cyber and real world: Examining the extent of cyber aggression experiences and its association with in-person dating violence. Journal of Interpersonal Violence, 33: 1071-95. doi:10.1177/0886260515614283

Oates, S., Gurevich, O., Walker, C., \& Di Meco, L. (2019). Running while female: Using Al to track how Twitter commentary disadvantages women in the 2020 U.S. Primaries. SSRN Electronic Journal. doi:10.2139/ssrn.3444200

Pew (Pew Research Center). (2021). The state of online harassment. https://www.pewresearch.org/internet/2021/01/13/the-state-of-online-harassment/

Plan International. (2020). Free to be online? Girls' and young women's experiences of online harassment. Surrey, UK: Plan International. https://planinternational.org/publications/freetobeonline

Posetti, J., Shabbir, N., Maynard, D., Bontcheva, K., \& Aboulez, N. (2021). The chilling: Global trends in online violence against women journalists. UNESCO Research Discussion Paper. https://unesdoc.unesco.org/ark:/48223/pf0000377223/PDF/377223eng.pdf.multi

Stanko, E. (1990). Everyday violence: How women and men experience sexual and physical danger. Pandora.

Suzor, N., Dragiewicz, M., Harris, B., Gillett, R., Burgess, J., \& Van Geelen, T. (2018). Human rights by design: The responsibilities of social media platforms to address gender-based violence online. Policy \& Internet, 11(1), 84-103. doi:10.1002/poi3.185

Thakur, D. and Hankerson, D. (2021). Facts and their discontents: A research agenda for online disinformation, race, and gender. Center for Democracy \& Technology.

https://cdt.org/insights/facts-and-their-discontents-a-research-agenda-for-onlinedisinformation-race-and-gender/

VAW Learning Network. (2013). Understanding technology-related violence against women: Types of violence and women's experiences. Learning Network Brief 6. https://www.vawlearningnetwork.ca/our-work/briefs/brief-06.html

Walklate, S. (2007). Imagining the victim of crime. Open University Press.

Web Foundation. (2020). The impact of online gender-based violence on women in public life. https://webfoundation.org/2020/11/the-impact-of-online-gender-based-violence-on-womenin-public-life/ 
WWWF and Girl Guides (World Wide Web Foundation \& World Association of Girl Guides). Girls Scouts survey: Young people's experience of online harassment. http://webfoundation.org/docs/2020/03/WF_WAGGGS-Survey-1-pager-1.pdf

\section{Suggested citation}

Hicks, J. (2021). Global evidence on the prevalence and impact of online gender-based violence. K4D Helpdesk Report. Institute of Development Studies. DOI: 10.19088/K4D.2021.140

\section{About this report}

This report is based on six days of desk-based research. The K4D research helpdesk provides rapid syntheses of a selection of recent relevant literature and international expert thinking in response to specific questions relating to international development. For any enquiries, contact helpdesk@k4d.info.

K4D services are provided by a consortium of leading organisations working in international development, led by the Institute of Development Studies (IDS), with the Education Development Trust, Itad, University of Leeds Nuffield Centre for International Health and Development, Liverpool School of Tropical Medicine (LSTM), University of Birmingham International Development Department (IDD) and the University of Manchester Humanitarian and Conflict Response Institute (HCRI).

This report was prepared for the UK Government's Foreign, Commonwealth \& Development Office (FCDO) and its partners in support of pro-poor programmes. Except where otherwise stated, it is licensed for non-commercial purposes under the terms of the Open Government Licence v3.0. K4D cannot be held responsible for errors or any consequences arising from the use of information contained in this report. Any views and opinions expressed do not necessarily reflect those of FCDO, K4D or any other contributing organisation.

(C) Crown copyright 2021.

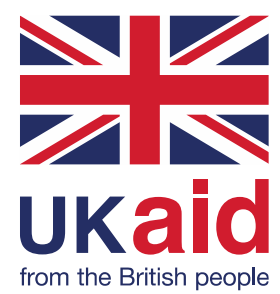

